\title{
Theoretical and experimental insight into zinc loading on mesoporous silica
}

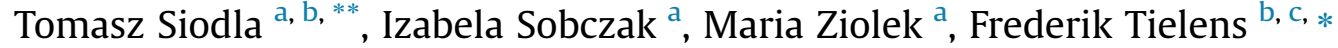 \\ ${ }^{a}$ Faculty of Chemistry, Adam Mickiewicz University, Umultowska 89b, 61-614 Poznań, Poland \\ b Sorbonne Universités, UPMC Univ. Paris 06, CNRS, Collège de France, Laboratoire de Chimie de la Matière Condensée de Paris (CMCP), 4 place Jussieu, F- \\ 75005 Paris, France \\ ${ }^{c}$ General Chemistry (ALGC), Vrije Universiteit Brussel (Free University Brussels-VUB), Pleinlaan 2, 1050 Brussel, Belgium
}

\section{A R T I C L E I N}

\section{Article history:}

Received 24 March 2017

Received in revised form

3 August 2017

Accepted 7 August 2017

Available online 12 August 2017

\section{Keywords:}

$\mathrm{Zn} / \mathrm{MCF}$

DFT

XPS

FTIR

Basicity

\begin{abstract}
A B S T R A C T
Zinc oxide species grafted on mesostructured cellular foam (MCF) silica are investigated using a combination of experimental and theoretical techniques. MCF is modelled using a realistic amorphous silica surface model surface slab. The most energetically favorable complexes grafted on the silica surface were identified and characterized at the molecular level. The $\mathrm{Zn}$ metal center was found in tetrahedral coordination. Moreover, the $\mathrm{Si}-\mathrm{O}-\mathrm{Zn}-\mathrm{OH}$ species is found to be stabilized in a 5 fold coordinated silicon with an unusual trigonal bipyramidal geometry. A mechanism for the grafting process of the metal species on the support is proposed.
\end{abstract}

\section{Introduction}

Zinc oxide is a modifier often used in silica and mesoporous silicas [1-5] for the generation of catalytic activity. In this perspective, zinc and copper, have been recently applied as modifiers to improve the catalytic activity of gold in AuCu-Zn/MCF catalyst [6]. It has been shown that zinc oxide loaded on MCF mesoporous silica strongly interacts with copper species, which leads to the incorporation of copper into the zinc oxide crystal structure. The easy penetration of copper into $\mathrm{ZnO}$ crystal lattice is explained by the similarity of the ionic radii of $\mathrm{Cu}^{2+}(0.73 \AA)$ and $\mathrm{Zn}^{2+}(0.74 \AA)[7,8]$. Moreover, the replacement of zinc by copper in $\mathrm{ZnO}$ crystallites resulted in changes in the properties of $\mathrm{AuCu}-\mathrm{Zn} /$ MCF catalyst. The interaction of zinc located in the support with reagents at one hand, and with the other modifiers, like gold or copper playing the role of active centers at the other hand, is

\footnotetext{
* Corresponding author. Sorbonne Universités, UPMC Univ. Paris 06, CNRS, Collège de France, Laboratoire de Chimie de la Matière Condensée de Paris (CMCP), 4 place Jussieu, F-75005 Paris, France.

** Corresponding author. Faculty of Chemistry, Adam Mickiewicz University, Umultowska 89b, 61-614 Poznań, Poland.

E-mail addresses: tsiodla@amu.edu.pl (T. Siodla), frederik.tielens@upmc.fr (F. Tielens).
}

strongly determined by the kind of favored (read the most stable) zinc species. Therefore the knowledge about such species is crucial. Usually $\mathrm{ZnO}$ crystalized in hexagonal wurzite structure (P63mc space group) is formed on the support surface. However, in many cases there are no diffraction peaks arising from $\mathrm{ZnO}$ in the XRD spectra of $\mathrm{ZnO} / \mathrm{SiO}_{2}$ catalyst indicating high dispersion of $\mathrm{ZnO}$, or even isolated $\mathrm{ZnO}$ monomers on the surface $[9,10]$.

$\mathrm{ZnO}$ is reported to show both basic and acidic properties and it can be called amphoteric [11]. Such solids usually display an interesting catalytic activity for dehydration or dehydrogenation reactions. However, upon catalytic reaction tests, $\mathrm{ZnO}$ was found to behave as basic catalyst $[12,13]$. It was proved that basic and Lewis acid sites as acid-base pairs on the $\mathrm{ZnO}$ surface are involved in basic heterogeneous catalysis (e.g. in the catalytic conversion of 2methylbut-3-yn-2-ol (MBOH) [7].

It is also important to note, that $\mathrm{ZnO}$ is a typical n-type semiconductor with a relatively wide band-gap $\left(E_{\mathrm{g}}=3.24 \mathrm{eV}\right.$ at $\left.300 \mathrm{~K}\right)$. This feature, as well as, non-toxicity and low cost, makes $\mathrm{ZnO}$ one of the most popular photocatalysts active in UV photocatalytic degradation of organic pollutants [8].

The molecular structure of $\mathrm{ZnO}$ species and mononuclear species in particular are ideal systems to be studied theoretically even as is the case of extreme dispersion. Up till now, there are no 
computational studies on monomeric $\mathrm{ZnO}$ species acting on silica surface. In our group amorphous silica has been studied using DFT on models for the silica support [14-17], and transition metal oxide catalysts supported on our silica models have been studied [18-26].

In this study we investigate silica supported zinc oxide monomers using periodic DFT calculations, and confront the results with experimental ones. A mechanism for the grafting process and most favorable $\mathrm{Zn}$ species formed on silica surface is proposed.

\section{Experimental}

\subsection{Preparation of catalysts}

Mesostructured cellular foam (MCF) was prepared by the onepot synthesis method proposed in Ref. [27]. At first, Pluronic 123 (Poly(ethylene glycol)-block-Poly(propylene glycol)-block-Poly(ethylene glycol)-block) ( $8 \mathrm{~g}, 1.4 \mathrm{mmol}$ ) was dissolved in $300 \mathrm{~g}$ of $0.7 \mathrm{M} \mathrm{HCl}$ solution at 308-313 K. Then 1,3,5-trimethylbenzene (Aldrich) (12 g, $99.84 \mathrm{mmol}$ ) and $\mathrm{NH}_{4} \mathrm{~F}$ (Aldrich) $(0.0934 \mathrm{~g}$, $2.52 \mathrm{mmol}$ ) were added upon vigorous stirring. Following $2 \mathrm{~h}$ of stirring, TEOS (tetraethoxysilane; Fluka) $(17.054 \mathrm{~g}, 81.99 \mathrm{mmol})$ was added. The final mixture was stirred at $308-313 \mathrm{~K}$ for $24 \mathrm{~h}$ and then transferred into a polypropylene bottle and heated at $373 \mathrm{~K}$ under static conditions for $24 \mathrm{~h}$. The solid product was recovered by filtration, washed with distilled water and dried at room temperature. The template was removed from the as-synthesized material by calcination at $773 \mathrm{~K}$ for $8 \mathrm{~h}$ under static conditions.

For the preparation of $\mathrm{Zn} / \mathrm{MCF}$, a portion of MCF material was treated by incipient wetness impregnation with an aqueous solution of $\mathrm{Zn}\left(\mathrm{NO}_{3}\right)_{2} \cdot 6 \mathrm{H}_{2} \mathrm{O}$ (Aldrich) and then for $20 \mathrm{~min}$ in ultrasonic bath. The amount of metal nitrate used for the impregnation was calculated to achieve the loading of zinc equal to $10 \mathrm{wt} \%$. The impregnated $\mathrm{Zn} / \mathrm{MCF}$ were dried at $353 \mathrm{~K}$ and then calcined at $773 \mathrm{~K}$ for $5 \mathrm{~h}$.

\subsection{Characterization of catalysts}

X-ray photoelectron spectroscopy (XPS) was performed on an Ultra-high vacuum photoelectron spectrometer based on Phoibos 150 NAP analyzer (Specs, Germany). The analysis chamber was operated under vacuum with a pressure close to $5.10^{-9} \mathrm{mbar}$ and the sample was irradiated with a monochromatic $\mathrm{Al} \mathrm{K \alpha}(1486.6 \mathrm{eV})$ radiation ( $15 \mathrm{kV} ; 10 \mathrm{~mA})$. The binding energy scales of all samples were corrected to the $\mathrm{Si} 2 \mathrm{p}$, with the known binding energy in $\mathrm{SiO}_{2}$ of $103.4 \mathrm{eV}$.

Infrared spectra were recorded on a Vertex 70 (Bruker) spectrometer (resolution $4 \mathrm{~cm}^{-1}$ ). The samples were dispersed in $\mathrm{KBr}$ pellet ( $1 \mathrm{mg}$ of the sample and $200 \mathrm{mg}$ of $\mathrm{KBr}$ ) with slight grinding. All spectra were recorded at room temperature in the range from 4000 to $400 \mathrm{~cm}^{-1}$.

The test reaction of 2,5-hexanedione cyclization was performed using $0.05 \mathrm{~g}$ of catalyst activated for $2 \mathrm{~h}$ at $623 \mathrm{~K}$ under nitrogen flow $\left(40 \mathrm{~cm}^{3} \mathrm{~min}^{-1}\right)$. After the activation process $0.5 \mathrm{~cm}^{3}$ of $2,5-$ hexanedione was passed continuously over the catalyst at $623 \mathrm{~K}$. The substrate was delivered with a pump system and vaporized before being passed through the catalyst with the flow of nitrogen carrier gas $\left(40 \mathrm{~cm}^{3} \mathrm{~min}^{-1}\right)$. The reaction products were collected for 30 min downstream of the reactor in the cold trap (a mixture of 2propanol and liquid nitrogen) and analyzed by gas chromatography (GC SRI 310C, DB1 column).

\subsection{Theoretical study}

\subsubsection{Computational details}

All geometry optimizations were performed using the ab initio plane-wave pseudopotential approach as implemented in VASP [28,29]. The Perdew-Burke-Ernzerhof (PBE) functional [30,31] was chosen to perform the periodic DFT calculations with an accuracy on the overall convergence tested elsewhere [14,19,20,24]. The positions of all the atoms in the super cell were relaxed until the total energy differences decrease below $10^{-4} \mathrm{eV}$. The atom positions as well as the unit cell parameters were relaxed.

Vibrational spectra were calculated for selected surface species within the harmonic approximation. Only the Zinc center and its first and second neighbors ( $\mathrm{O}-\mathrm{Si}$ and $\mathrm{OH}$ groups) were allowed to move, the support was kept fixed. The Hessian matrix was computed by the finite difference method followed by the diagonalization procedure. The eigenvalues of the resulting matrix lead to the frequency values. The assignment of the vibrational modes was made by inspection of the corresponding eigenvectors.

\subsubsection{Model description}

The hydrated $27 \mathrm{SiO}_{2}$ model [14] containing 13 (for models containing $\mathrm{Si}-\mathrm{O}-\mathrm{Zn}-\mathrm{OH}$ species) and 12 water molecules (for models containing Si-O-Zn-O-Si species) were used to graft $1 \mathrm{ZnO}$ per unit cell. These species were considered products of the following reactions:

$\operatorname{surf}_{\mathrm{A}}-\mathrm{OH}+\mathrm{ZnO} \rightarrow \operatorname{surf}_{\mathrm{A}}-\mathrm{O}-\mathrm{Zn}-\mathrm{OH}$

$\mathrm{HO}-\operatorname{surf}_{\mathrm{A}}-\mathrm{OH}+\mathrm{ZnO} \rightarrow \operatorname{surf}_{\mathrm{B}}-\mathrm{O}-\mathrm{Zn}-\mathrm{O}-\operatorname{surf}_{\mathrm{B}}+\mathrm{H}_{2} \mathrm{O}$

where "surf $f_{A}$ " and "surf ${ }_{B}$ " stands for the $\left[\left(\mathrm{SiO}_{2}\right)_{27}\left(\mathrm{H}_{2} \mathrm{O}\right)_{13}\right]$ surface and $\left[\left(\mathrm{SiO}_{2}\right)_{27}\left(\mathrm{H}_{2} \mathrm{O}\right)_{12}\right]$ surface, respectively.

The silica model reproduces the experimentally established ring size distribution, $\mathrm{Si}-\mathrm{O}-\mathrm{Si}$ and $\mathrm{O}-\mathrm{Si}-\mathrm{O}$ angles, overall density of silanol groups and partition into several types (isolated, associated, geminate). The unit cell dimensions of the model are $11.89 \times 16.57 \times 25.53 \AA^{3}$ as optimized for the mono-grafted $\mathrm{Zn}$ on the amorphous silica support having an hydroxyl group on the metal center with coordination number equal to 2 (Fig. 1, also see section 3.2, Fig. 4: T c.n. $=\mathbf{2}$ ). For quality/cost reasons, those unit cell dimensions have been fixed during the optimization of the various different geometrical configurations of the $\mathrm{ZnO}$ species grafted on amorphous silica. It is computationally justified to compare the energy values of the unit cells of the same size. Due to the flexibility of the silica surface, other species can be easily accommodated. Furthermore, to get an insight into the impact of $\mathrm{ZnO}$ species on silica surface, the unit cell parameters were recalculated for the silica model alone. Then, the unit cell dimensions of the "pure" silica are $12.77 \times 17.64 \times 25.17 \AA^{3}$. Such result is suggesting the slight contraction of the silica surface while $\mathrm{ZnO}$ species are grafted.

\section{Results and discussion}

3.1. Experimental evidence for the presence of $\mathrm{Zn}-\mathrm{OH}$ species on the surface of mesoporous MCF silica

The experiments were performed using mesoporous cellular foam (MCF).

The MCF used as a support for zinc species possesses high surface area $\left(608 \mathrm{~m}^{2} \mathrm{~g}^{-1}\right)$ and pores with typical diameters of $16.8 \mathrm{~nm}$ for the windows and $37.2 \mathrm{~nm}$ for the cells. Mesoporous Cellular Foam possess the highest size of pores among mesoporous molecular sieves (e.g. MCM-41 - ca. 3-5 nm, SBA-15 - ca. 8-10 nm). 
The silica surface on which the anchoring of metal species occurs contains silanol groups. To identify the acidic or basic nature of $\mathrm{OH}$ groups on the surface of $\mathrm{Zn} / \mathrm{MCF}$, the 2,5-hexanedione (DHN) cyclization and dehydration reaction was performed over the catalyst. This reaction has been proposed by Dessau [32] as Brønsted acid-base test. The formation of 2,5-dimethylfuran (DMF) occurs on acidic centers, whereas basic ones take part in the production of 3-methyl-2-cyclopentenone (MCP). According to literature $[32,33]$ the catalyst is considered basic if MCP/DMF selectivity ratio $\gg 1$. When $\mathrm{MCP} / \mathrm{DMF} \ll 1$ the catalyst exhibits acidic properties, while for $\mathrm{MCP} / \mathrm{DMF} \approx 1$ the acid - base character of the catalysts is postulated.

The results given in Table 1 indicate that $\mathrm{Zn} / \mathrm{MCF}$ catalyst reveals basic character i.e. contain basic $\mathrm{OH}$ groups. MCP/DMF ratio is well above 1 . Selectivity to MCP, which is formed on Brønsted basic centers, is very high (>90\%). Basicity is also characteristic of silanol groups in MCF material, but activity of this sample is much lower than that one observed for $\mathrm{Zn} / \mathrm{MCF}$, which consequently indicates that the grafting of zinc oxide species onto MCF support enhances the basicity originating from $\mathrm{OH}$ groups.

To get a deeper insight into the character of the species formed and their catalytic activity, XPS and FTIR studies were performed.

XPS results directly indicate the formation of $\mathrm{Zn}-\mathrm{OH}$ groups on the surface of Zn/MCF sample (See Fig. 2). In the 01s XPS region one can observe the intense peak at ca. $532.7 \mathrm{eV}$ with a tail at higher and lower binding energies. The deconvolution allows distinction of four components, two main at 533.3 and $532.2 \mathrm{eV}$ and two additional (low intensity) ones at 534.5 and $530.6 \mathrm{eV}$. The most intense bands can be assigned to the oxygen in the silica structure, $\mathrm{Si}-\mathrm{O}-\mathrm{Si}(\mathrm{BE}=533.3 \mathrm{eV})[34,35]$ and oxygen of the hydroxyls groups bonded with zinc (surface $\mathrm{Zn}-\mathrm{OH}),(\mathrm{BE}=532.2 \mathrm{eV})[11,12,36]$. The bands at 534.5 and $530.6 \mathrm{eV}$ can be attributed to oxygen in $\mathrm{Zn}-\mathrm{OH}$ bonded to $\mathrm{Si}-\mathrm{O}-\mathrm{Si}(\mathrm{Si}-\mathrm{O}-\mathrm{Zn}-\mathrm{OH})$ and oxygen in $\mathrm{Zn}-\mathrm{O}-\mathrm{Si}$, respectively (both identified by DFT calculations) $[11,12,36]$.

FTIR spectra of MCF and Zn/MCF samples (See Fig. 3) show bands characteristic for mesoporous silica and silica MCF in the region of $1500-400 \mathrm{~cm}^{-1}$ [37]. Besides the bands corresponding to the Si-OSi vibrations (1086, 804 and $468 \mathrm{~cm}^{-1}$ ) a band at $962 \mathrm{~cm}^{-1}$ is observed. This band is assigned to vibrations associated to the silanol groups ( $\mathrm{Si}-\mathrm{O}-\mathrm{Si}-\mathrm{OH}$ vibrations), which is found to be more intense in the spectrum of pure silica MCF. The ratios (R) of the absorbance of the structural band at $804 \mathrm{~cm}^{-1}$ to the band at $962 \mathrm{~cm}^{-1}$ for the samples studied are given in Table 2 . The lower $\mathrm{R}$ value the higher the number of $\mathrm{Si}-\mathrm{OH}$ groups involved. The ratio $(\mathrm{R})$ has ca. a twice larger value for Zn/MCF than for MCF, indicating the participation of silanol groups in the anchoring of zinc species.

The vibrations of the $\mathrm{Zn}-\mathrm{O}-\mathrm{H}$ and $\mathrm{Zn}-\mathrm{O}-\mathrm{Si}$ arrangements were calculated. The obtained values are in following ranges: 987-1008/ 3571 - $3572 \mathrm{~cm}^{-1}$ for stretching/bending $\mathrm{ZnO}-\mathrm{H}$ vibrations, 508-541/659 - $678 \mathrm{~cm}^{-1}$ for SiO-Zn-OH symmetric/asymmetric stretching and $60-82 / 226-266 \mathrm{~cm}^{-1}$ for SiO-Zn-OH bending vibrations with Zinc/Oxygens motion mode respectively. Unluckily, those frequencies are not exhibited in FTIR spectrum of Zn/MCF which - beside the difference in intensity of silanols - is pretty much the same as the FTIR spectrum of pure MCF (vibrations of Si$\mathrm{O}-\mathrm{Si}$ ).

The above observation allows concluding about the mode of interaction of the modifier with the silica surface in MCF material. The results obtained point out that zinc species interact with silanol groups and are chemically bonded to the silica surface. The silanol groups are involved in the interaction with zinc species in $\mathrm{Zn} / \mathrm{MCF}$. The interaction of metal species with the silanol groups lead to the bonding between the metal and a $\mathrm{OH}$ group.
3.2. Computational study of preferable species formed after $\mathrm{ZnO}$ loading on silica

In order to get a deeper insight into zinc oxide interaction with silica we confronted the experimental findings with theoretical ones. Several geometrical configurations of $\mathrm{ZnO}$ species grafted on amorphous silica were systematically investigated (See Fig. 4) and can be divided into three different groups with different degrees of hydration: terminal $(\mathrm{T})(\mathrm{Si}-\mathrm{O}-\mathrm{Zn}-\mathrm{OH})$ grafted on a single $\mathrm{Si}-\mathrm{OH}$, vicinal $(\mathrm{V})(\mathrm{Si}-\mathrm{O}-\mathrm{Zn}-\mathrm{O}-\mathrm{Si})$ grafted on a $\mathrm{HO}-\mathrm{Si}-\mathrm{O}-\mathrm{Si}-\mathrm{OH}$ moiety, geminal $(\mathrm{G})(\mathrm{Si}-\mathrm{O}-\mathrm{Zn}-\mathrm{O}-\mathrm{Si}$ ) grafted on a $\mathrm{HO}-\mathrm{Si}-\mathrm{OH}$ moiety and isolated $(\mathrm{I})(\mathrm{Si}-\mathrm{O}-\mathrm{Zn}-\mathrm{O}-\mathrm{Si})$ grafted on a two $\mathrm{Si}-\mathrm{OH}$ groups not directly connected.

Moreover, the different coordination numbers, (c.n.): 2, 3 or 4, of the $\mathrm{Zn}$ atom were also considered (See Fig. 4). Due to the flexibility of the silica surface, these species can be easily accommodated as is the case for other transition metals [18,21-24,26]. A series of models with different geometries were calculated and compared on the basis of their total energy. Interesting to note is that some $\mathrm{Zn}$ species transformed without energy barrier to another geometrical arrangement, indicated with "n/a" in Fig. 4. The geometrical optimization of these non-minimum energy geometries for some coordinations transformed them to the structures having different c.n.

The mono-grafted $\mathrm{Zn}$ oxide species on the amorphous silica support having an hydroxyl group on the metal center, prefers a coordination number equal to 4 (tetrahedral configuration), as well as those without an hydroxyl group, i.e. di-grafted $\mathrm{Zn}$ oxide species having an isolated configuration (I) of $\mathrm{Si}-\mathrm{O}-\mathrm{Zn}-\mathrm{O}-\mathrm{Si}$ moiety again with c.n. $=4$ as concluded from the lowest energies. However, 
because of the small energy difference, the other isomeric structures (with different c.n.) are probably also present. It should be noted, that the energy values, given in Fig. 4, do not show a clear cut trend when with increasing c.n. from 2 to 4 . This is because in order to obtain structures having different c.n. the $\mathrm{Zn}$ oxide has to be grafted on different sites on the amorphous silica surface. All grafting sites were carefully chosen to obtain desired configuration and c.n without any significant changes of the initial silica slab. This way we can avoid large errors in comparison of energies for models having different silica frames significantly modified by relaxation.

Considering the reaction energies given on Fig. 4 calculated according to eqn (1) or (2) for the best grafting modes as a function of hydration rate. For $\mathrm{Zn}$ oxide values of -5.23 and $-4.05 \mathrm{eV}$ for 0 and -1 water molecules are obtained, corresponding to the models having configurations (T, c.n. $=4$ ) and (I, c.n. $=4$ ) respectively (see Fig. 4). All reaction energies are exothermic for grafting $\mathrm{ZnO}$, indicating that such adsorption is favored. Similar calculations have been recently reported for the cases of grafting $\mathrm{Cr}$, Mo, and $\mathrm{W}$ oxides $[18,21-24,26]$. It has been shown that the adsorption of the $\mathrm{MO}_{2}(\mathrm{OH})_{2}$ with $\mathrm{M}=\mathrm{Cr}$, Mo, or $\mathrm{W}$, is most favored for $\mathrm{W}$ compared with $\mathrm{Mo}$ and $\mathrm{Cr}$, with respect to the initial situation (hydroxylated silica and $\mathrm{H}_{2} \mathrm{MO}_{4}$ in the gas phase). The most favorable reaction was found for the adsorption of the $\mathrm{WO}_{2}(\mathrm{OH})_{2}$ transition metal precursor and a water molecule, yielding an exothermic energy of $-2.71 \mathrm{eV}$. Just for the sake of comparison, the adsorption of $\mathrm{ZnO}$ is calculated to be more exothermic $(-5.23 \mathrm{eV})$, beside the fact that the precursors have different nature $\left(\mathrm{ZnO}\right.$ vs $\left.\mathrm{H}_{2} \mathrm{WO}_{4}\right)$.

The bond lengths and bond angles have been calculated both for mono and di-grafted $\mathrm{Zn}$ atoms on a silica surface. The optimized mono-grafted structures have a $\mathrm{Zn}-\mathrm{OH}$ bond length of $1.80-1.95 \AA$, $\mathrm{ZnO}-\mathrm{H}$ bond length of $0.97 \AA$, and $\mathrm{SiO}-\mathrm{Zn}$ bond lengths of 1.81-1.91 A., while usually Si-O bond length in silica is about $1.62 \AA$. The $\mathrm{Zn} \cdots \mathrm{O}$ coordination distances are here between 2.08 and $2.65 \AA$ A. The isolated (I) di-grafted $\mathrm{Zn}$-oxide species have a $\mathrm{Zn}$-OSi bond length of $1.79-1.88 \AA$ and $\mathrm{Zn} \cdots \mathrm{O}$ coordination distances of $2.26-2.51 \AA$.

In order to get a more precise picture of the respective stabilities of the mono- and di-grafted species at the silica surface, we performed calculations using an atomistic thermodynamics approach. Introducing appropriate chemical potentials to calculate an approximation of the Gibbs free energy, deviations in surface composition and the presence of gas phases have been taken into consideration in the same way as it has been done earlier [24]. Assuming that the surface is in thermodynamic equilibrium with the gas phase, the chemical potentials are related to a given temperature $T$ and pressure $\mathrm{p}$. This procedure enables us to bridge the gap between ultra-high vacuum like conditions and realistic catalytic conditions. For this purpose the following equation is considered (where "Si-O-Zn-OH" and "Si-O-Zn-O-Si" terms stand for appropriate silica slabs):

$$
\mathrm{Si}-\mathrm{O}-\mathrm{Zn}-\mathrm{OH} \rightarrow \mathrm{Si}-\mathrm{O}-\mathrm{Zn}-\mathrm{O}-\mathrm{Si}+\mathrm{H}_{2} \mathrm{O}_{\text {gas }}
$$

It is assumed that the zinc/silica system is in contact with a gaseous water and from the electronic energy, the free energy of the water/zinc/silica interface under known thermodynamic conditions may be estimated following the approximations used in earlier studies $[21,23,26]$. In the proposed scheme, the free energy of water (including the ZPE correction) in the gas phase is:

$\Delta G\left(\mathrm{H}_{2} \mathrm{O}\right)=E\left(\mathrm{H}_{2} \mathrm{O}\right)-\left(\left(\Delta H_{\mathrm{G}}-T \Delta S_{\mathrm{G}}(T)\right)+\mathrm{RT} \ln \left(\mathrm{p} / \mathrm{p}^{0}\right)\right)$

where $E\left(\mathrm{H}_{2} \mathrm{O}\right)$ is the electronic energy of water calculated at $0 \mathrm{~K}$, $\Delta H_{\mathrm{G}}$ and $\Delta S_{\mathrm{G}}(T)$ are the enthalpy and entropy of gaseous water, calculated using the Gaussian09 code as a function of the temperature, $\mathrm{p}$ is the partial pressure of water vapor and $\mathrm{p}^{0}$ is the standard pressure ( 1 bar).

Using the above-mentioned formalism, the free energy of reaction (3), for the formation of the di-grafted zinc complexes from the mono-grafted one under equilibrium conditions, is then expressed as:

$\Delta G=E(\mathrm{Si}-\mathrm{O}-\mathrm{Zn}-\mathrm{O}-\mathrm{Si})+\Delta G\left(\mathrm{H}_{2} \mathrm{O}_{\text {gas }}\right)-E(\mathrm{Si}-\mathrm{O}-\mathrm{Zn}-\mathrm{OH})$

In this approach, it is assumed that the energy of the mono to digrafted transition is independent of the degree of hydration of the silica surface. On this basis, the Gibbs free energy of the reaction presented in Fig. 3 (eq. (3)) was calculated, and a phase diagram was drawn (See Fig. 5) showing the stability ranges of the different grafting geometries.

Below $500 \mathrm{~K}$ the most stable structure is the most hydrated one containing a $\mathrm{Zn}-\mathrm{OH}$ group, and above $500 \mathrm{~K}$ the most stable structures are those formed after the elimination of a water molecule.

Finally it is noteworthy that the most stable species of $\mathrm{ZnO}$ on the surface of amorphous silica was found to have neighboring silicon atoms in an unusual pentacoordinated (hexahedral) trigonal bipyramidal geometry (Fig. 6). Silicon compounds with a coordination number higher than four have been known since the early 19th century [36]. The chemistry of pentacoordinate silicon(IV) complexes with $\mathrm{SiO}_{5}$ skeletons is dominated by ionic species [35]. However rigid and favorable geometries - like in our case of intramolecular coordination - help allowing interactions with neutral donors [34], while most cases of intermolecular donation are either too weak to interact, or results in complete anionic dissociation to form a new tetravalent complex.

A formation mechanism for the grafting of the $\mathrm{Zn}$ oxide on amorphous silica support is proposed and confirmed by calculations. A single zinc oxide molecule can interact with silica surface without any energy barrier according to the presented mechanism (See Fig. 7).

The presented theoretical study indicates that the most stable structure of zinc oxide grafted to amorphous silica forms Si-O-Zn$\mathrm{OH}$ species. Such species were found to reveal catalytic activity in basic catalyzed reaction, 2,5-DHN dehydration and cyclization.

\section{Conclusions}

The molecular structure of grafted monomeric species of $\mathrm{ZnO}$ on hydroxylated amorphous silica used as a model for MCF is studied using periodic DFT. The effect of hydration on the molecular structure's geometry and chemistry was investigated and confronted with experimental data from XPS and FTIR. The presence of $\mathrm{ZnOH}$ groups was confirmed. The dehydration of $\mathrm{ZnO}$ is predicted to occur around $500 \mathrm{~K}$, by means of an atomistic thermodynamics approach. The grafting of the $\mathrm{ZnO}$ precursor, due to its structure can only be grafted 
via one $\mathrm{Si}-\mathrm{O}-\mathrm{Zn}$ bond, and is thus much less dependent on the silanol density of the support than other transition metal precursors. Indeed, the oxidation state of $\mathrm{Zn}$ omits the need of having several silanols close to each other, such as a silanol nest, to be grafted.

We have also pointed out the probability of existence of an unusual stable species with $\mathrm{Si}$ atom in trigonal bipyramidal geometry. The plausible mechanisms for the anchoring metal oxides on the silica surface has been thermodynamically confirmed by calculation.

Another aim of this study has been reached since it was the construction of a realistic and calculable (periodic DFT level) structure representing $\mathrm{Zn}$ oxides species supported on amorphous silica. With this model the investigation of its reactivity (transition states and reaction paths) will be possible for a series of important reactions, as mentioned in the Introduction.

\section{Acknowledgements}

National Science Centre in Poland (Grant No. 2013/10/E/ST5/ 00642) is acknowledged for the financial support of this work. This work was performed using HPC resources from GENCI-[CCRT/ CINES/IDRIS] (Grant 2016-[x2016082022]) and the CCRE of Université Pierre et Marie Curie. This research was also supported in part by PL-Grid Infrastructure.

\section{References}

[1] X.N. Hou, S.J. Qing, Y.J. Liu, H.J. Xi, T.F. Wang, X. Wang, Z.X. Gao, Reshaping CuO on silica to generate a highly active $\mathrm{Cu} / \mathrm{SiO} 2$ catalyst, Catal. Sci. Technol. 6 (2016) 6311-6319.

[2] J.M. Fraile, K. Le Jeune, J.A. Mayoral, N. Ravasio, F. Zaccheria, Cuo/Sio2 as a simple, effective and recoverable catalyst for alkylation of indole derivatives with diazo compounds, Org. Biomol. Chem. 11 (2013) 4327-4332.

[3] M. Imran, K.G. Lee, Q. Imtiaz, B.K. Kim, M. Han, B.G. Cho, D.H. Kim, Metaloxide-doped silica nanoparticles for the catalytic glycolysis of polyethylene terephthalate, J. Nanosci. Nanotechnol. 11 (2011) 824-828.

[4] M.W.E. van den Berg, S. Polarz, O.P. Tkachenko, K.V. Klementiev, M. Bandyopadhyay, L. Khodeir, H. Gies, M. Muhler, W. Grunert, Cu/ZnO aggregates in siliceous mesoporous matrices: development of a new model methanol synthesis catalyst, J. Catal. 241 (2006) 446-455.

[5] J. Florek-Milewska, P. Decyk, M. Ziolek, Catalytic properties of Cu/SBA-3 in oxidative dehydrogenation of methanol-the effect of the support composition, Appl. Catal. Gen. 393 (2011) 215-224.

[6] I. Bilkova, I. Sobczak, P. Decyk, M. Ziolek, J.E. Whitten, The effect of zinc and copper in gold catalysts supported on mcf cellular foams on surface properties and catalytic activity in methanol oxidation, Microporous Mesoporous Mater. 232 (2016) 97-108.

[7] C. Drouilly, J.M. Krafft, F. Averseng, H. Lauron-Pernot, D. Bazer-Bachi, C. Chizallet, V. Lecocq, G. Costentin, Role of oxygen vacancies in the basicity of $\mathrm{ZnO}$ : from the model methylbutynol conversion to the ethanol transformation application, Appl. Catal. Gen. 453 (2013) 121-129.

[8] Y. Peng, Y. Wang, Q.G. Chen, Q. Zhub, A.W. Xu, Stable yellow zno mesocrystals with efficient visible-light photocatalytic activity, Crystengcomm 16 (2014) $7906-7913$.

[9] K. Qian, W. Huang, J. Fang, S. Lv, B. He, Z. Jiang, S. Wei, Low-temperature CO oxidation over Au/ZnO/SiO2 catalysts: some mechanism insights, J. Catal. 255 (2008) 269-278.

[10] N.W.C. Jusoh, A.A. Jalil, S. Triwahyono, A.H. Karim, N.F. Salleh, N.H.R. Annuar, N.F. Jaafar, M.L. Firmansyah, R.R. Mukti, M.W. Ali, Structural rearrangement of mesostructured silica nanoparticles incorporated with ZnO catalyst and its photoactivity: effect of alkaline aqueous electrolyte concentration, Appl. Surf. Sci. 330 (2015) 10-19.

[11] J. Goldwasser, W.K. Hall, Studies of acid-base-catalyzed reactions .14. Isomerization of butene over La2O3 and ZnO, J. Catal. 71 (1981) 53-63.

[12] H. Lauronpernot, F. Luck, J.M. Popa, Methylbutynol - a new and simple diagnostic-tool for acidic and basic sites of solids, Appl. Catal. 78 (1991) $213-225$

[13] C. Lahousse, J. Bachelier, J.C. Lavalley, H. Lauronpernot, A.M. Legovic, Validity of using isopropanol decomposition as a test-reaction for the characterization of metal-oxides basicity - comparison with results obtained from methylbutynol decomposition, J. Mol. Catal. 87 (1994) 329-332.

[14] F. Tielens, C. Gervais, J.F. Lambert, F. Mauri, D. Costa, Ab initio study of the hydroxylated surface of amorphous silica: a representative model, Chem. Mater. 20 (2008) 3336-3344.

[15] A. Cimas, F. Tielens, M. Sulpizi, M.P. Gaigeot, D. Costa, The amorphous silicaliquid water interface studied by ab initio molecular dynamics (AIMD): local organization in global disorder, J. Phys. Condens. Matter 26 (2014) 244106.

[16] M. Pfeiffer-Laplaud, D. Costa, F. Tielens, M.P. Gaigeot, M. Sulpizi, Bimodal acidity at the amorphous silica/water interface, J. Phys. Chem. C 119 (2015) $27354-27362$.

[17] M. Gierada, I. Petit, J. Handzlik, F. Tielens, Hydration in silica based mesoporous materials: a dft model, Phys. Chem. Chem. Phys. 18 (2016) 32962-32972.
[18] M.M. Islam, D. Costa, M. Calatayud, F. Tielens, Characterization of supported vanadium oxide species on silica: a periodic dft investigation, J. Phys. Chem. C 113 (2009) 10740-10746.

[19] A. Wojtaszek, I. Sobczak, M. Ziolek, F. Tielens, Gold grafted to mesoporous silica surfaces, a molecular picture, J. Phys. Chem. C 113 (2009) 13855-13859.

[20] A. Wojtaszek, I. Sobczak, M. Ziolek, F. Tielens, The formation of gold clusters supported on mesoporous silica material surfaces: a molecular picture, J. Phys. Chem. C 114 (2010) 9002-9007.

[21] H. Guesmi, F. Tielens, Chromium oxide species supported on silica: a representative periodic dft model, J. Phys. Chem. C 116 (2012) 994-1001.

[22] J. Handzlik, R. Grybos, F. Tielens, Structure of monomeric chromium(vi) oxide species supported on silica: periodic and cluster DFT studies, J. Phys. Chem. C 117 (2013) 8138-8149.

[23] H. Guesmi, R. Gryboś, J. Handzlik, F. Tielens, Characterization of molybdenum monomeric oxide species supported on hydroxylated silica; a DFT study, Phys. Chem. Chem. Phys. 16 (2014) 18253-18260.

[24] D.C. Tranca, A. Wojtaszek-Gurdak, M. Ziolek, F. Tielens, Supported and inserted monomeric niobium oxide species on/in silica: a molecular picture, Phys. Chem. Chem. Phys. 17 (2015) 22402-22411.

[25] M. Gierada, P. Michorczyk, F. Tielens, J. Handzlik, Reduction of chromia-silica catalysts: a molecular picture, J. Catal. 340 (2016) 122-135.

[26] H. Guesmi, R. Grybos, J. Handzlik, F. Tielens, Characterization of tungsten monomeric oxide species supported on hydroxylated silica; a DFT study, Rsc Adv. 6 (2016) 39424-39432.

[27] P. Schmidt-Winkel, W.W. Lukens, P.D. Yang, D.I. Margolese, J.S. Lettow, J.Y. Ying, G.D. Stucky, Microemulsion templating of siliceous mesostructured cellular foams with well-defined ultralarge mesopores, Chem. Mater. 12 (2000) 686-696.

[28] G. Kresse, J. Hafner, Ab-initio molecular-dynamics simulation of the liquidmetal amorphous-semiconductor transition in germanium, Phys. Rev. B 49 (1994) 14251-14269.

[29] G. Kresse, J. Hafner, Ab-initio molecular-dynamics for liquid-metals, Phys. Rev. B 47 (1993) 558-561.

[30] J.P. Perdew, K. Burke, M. Ernzerhof, Generalized gradient approximation made simple (vol 77, pg 3865, 1996), Phys. Rev. Lett. 78 (1997), 1396-1396.

[31] J.P. Perdew, K. Burke, M. Ernzerhof, Generalized gradient approximation made simple, Phys. Rev. Lett. 77 (1996) 3865-3868.

[32] R.M. Dessau, Base-catalyzed and acid-catalyzed cyclization of diketones over ZSM-5, Zeolites 10 (1990) 205-206.

[33] J.J. Alcaraz, B.J. Arena, R.D. Gillespie, J.S. Holmgren, Solid base catalysts for mercaptan oxidation, Catal. Today 43 (1998) 89-99.

[34] K.D. Onan, A.T. McPhail, C.H. Yoder, R.W. Hillyard, Structure of compound purported to Be nn-bis(chloromethyldimethylsilyl)-acetamide - X-ray crystalstructure analysis of novel 5-membered oxygen-containing, silicon-containing, and nitrogen-containing heterocycle (O-Si)-Chloro- (N-Chlorodimethylsilylacetamido)Methyl dimethylsilane, J. Chem. Soc. Chem. Commun. (1978) 209-210.

[35] O. Seiler, C. Burschka, T. Fenske, D. Troegel, R. Tacke, Neutral hexa- and pentacoordinate silicon(iv) complexes with $\mathrm{SiO} 6$ and SiO4n skeletons, Inorg. Chem. 46 (2007) 5419-5424.

[36] S. Rendler, M. Oestreich, Hypervalent silicon as a reactive site in selective bond-forming processes, Synth. Stuttg. (2005) 1727-1747.

[37] R.K. Rana, B. Viswanathan, Catal. Lett. 52 (1998) 25-29.
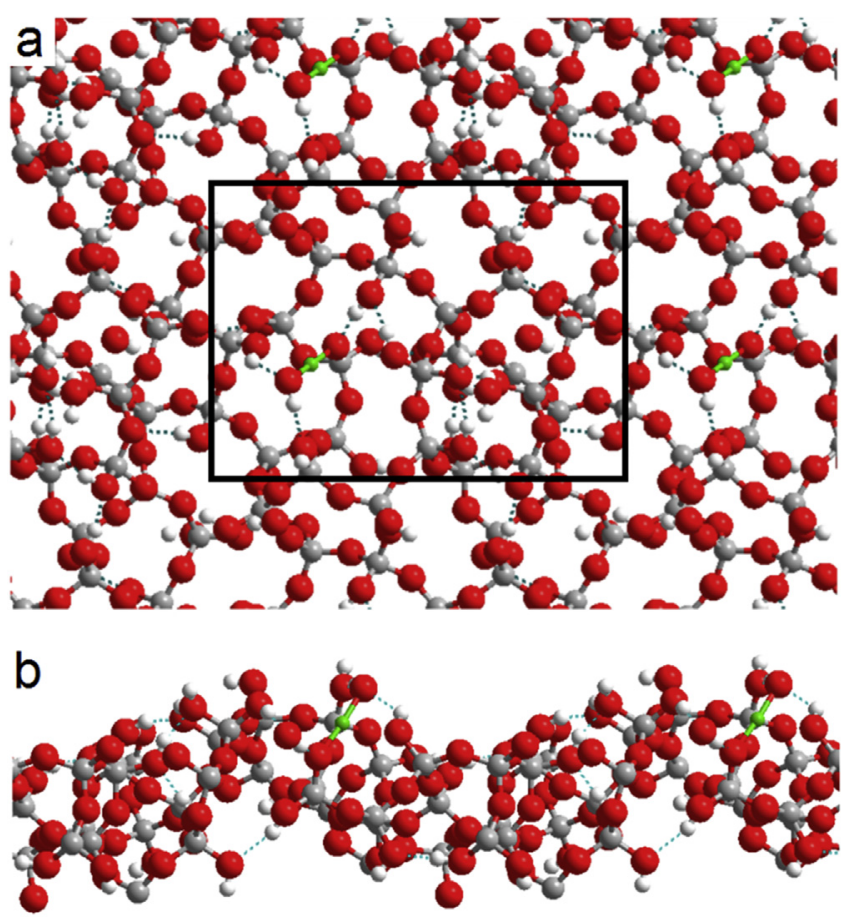

Fig. 1. Model for the amorphous silica surface used in this work, for supported $\mathrm{Zn}$ oxide species grafted onto a silica surface showing the double unit cell dimensions, (a) top view and (b) side view of selected structure. Color code: H: white; O: red; Si: gray; $\mathrm{Zn}$ : green. (For interpretation of the references to colour in this figure legend, the reader is referred to the web version of this article.) 


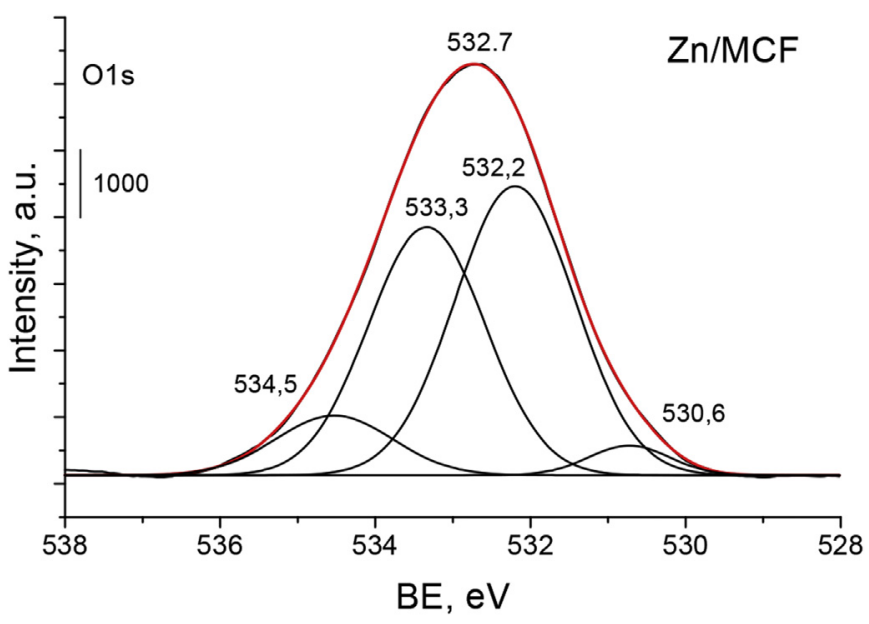

Fig. 2. XP spectra of oxygen 0 1s (binding energies indicated).

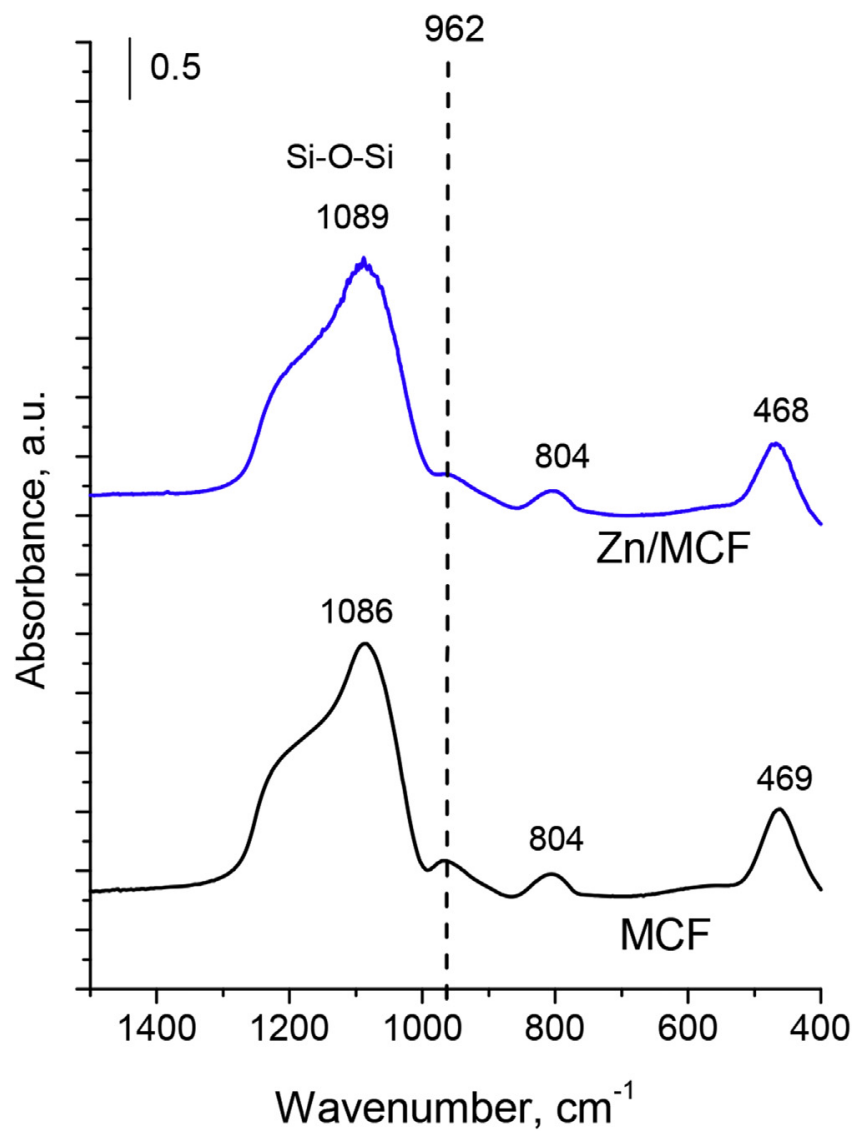

Fig. 3. FTIR spectra of pristine MCF and the material modified with zinc species.

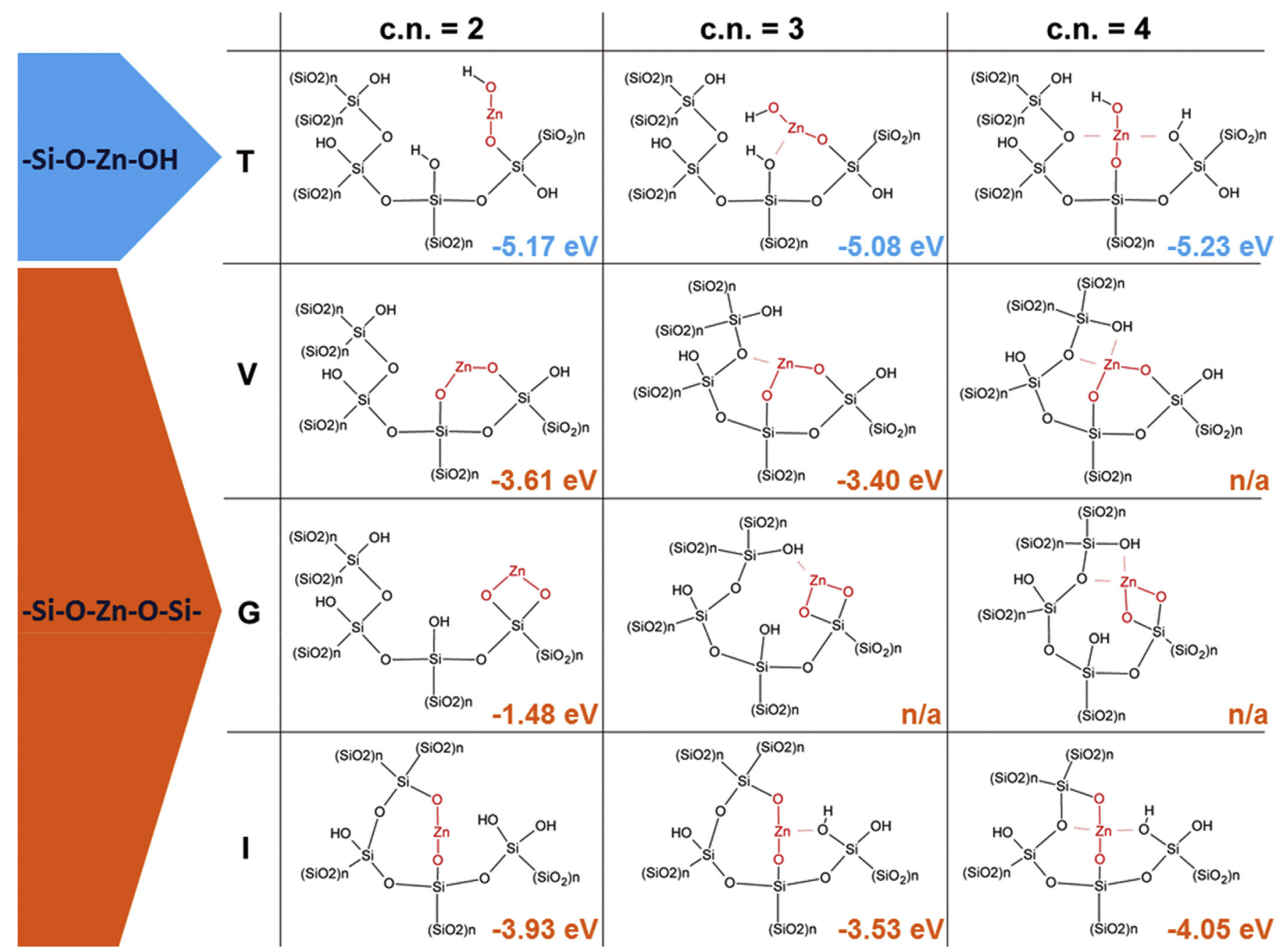

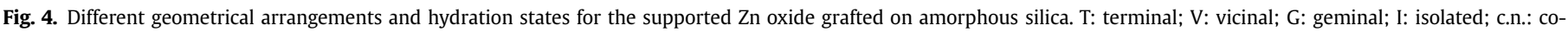
ordination number. Energy values were calculated using eqn (1) or (2) for formation of -Si-O-Zn-OH or -Si-O-Zn-O-Si arrangement, respectively. 
Table 1

Activity and selectivity of 2,5-DHN dehydration and cyclization reaction performed on pure MCF and MCF modified by grafting of zinc species.

\begin{tabular}{|c|c|c|c|c|}
\hline Catalyst & DHN conversion, $\%$ & MCP selectivity, \% & DMF selectivity, \% & $\mathrm{MCP} / \mathrm{DMF}$ \\
\hline $\mathrm{Zn} / \mathrm{MCF}$ & 40 & 91 & 9 & 10.1 \\
\hline MCF & 2 & 52 & 48 & 1.1 \\
\hline
\end{tabular}

Table 2

The ratios (R) of structural bands (Si-O-Si: Si-OH) shown in FTIR spectra of MCF and $\mathrm{Zn} / \mathrm{MCF}$.

\begin{tabular}{ll}
\hline Catalyst & $\mathrm{R}=\mathrm{A}_{804} \mathrm{~cm}^{-1} / \mathrm{A}_{962} \mathrm{~cm}^{-1}$ \\
\hline $\mathrm{MCF}$ & 1.3 \\
$\mathrm{Zn} / \mathrm{MCF}$ & 2.7 \\
\hline
\end{tabular}

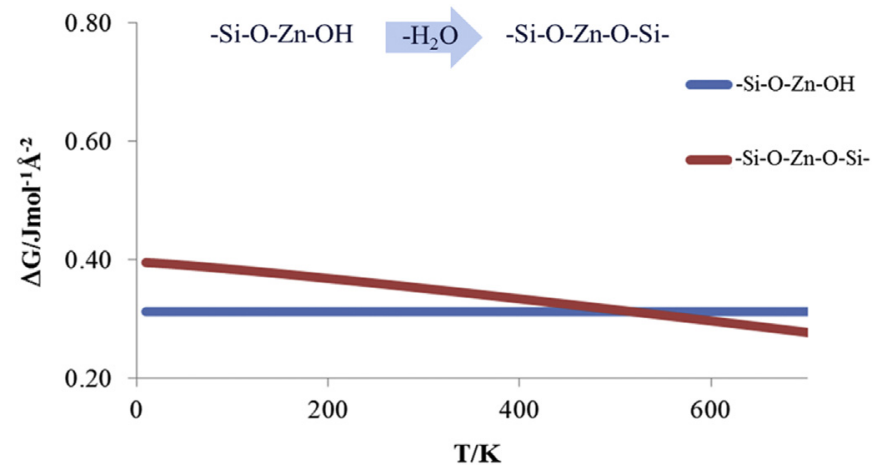

Fig. 5. Phase diagram showing the stability ranges for the different grafting geometries.
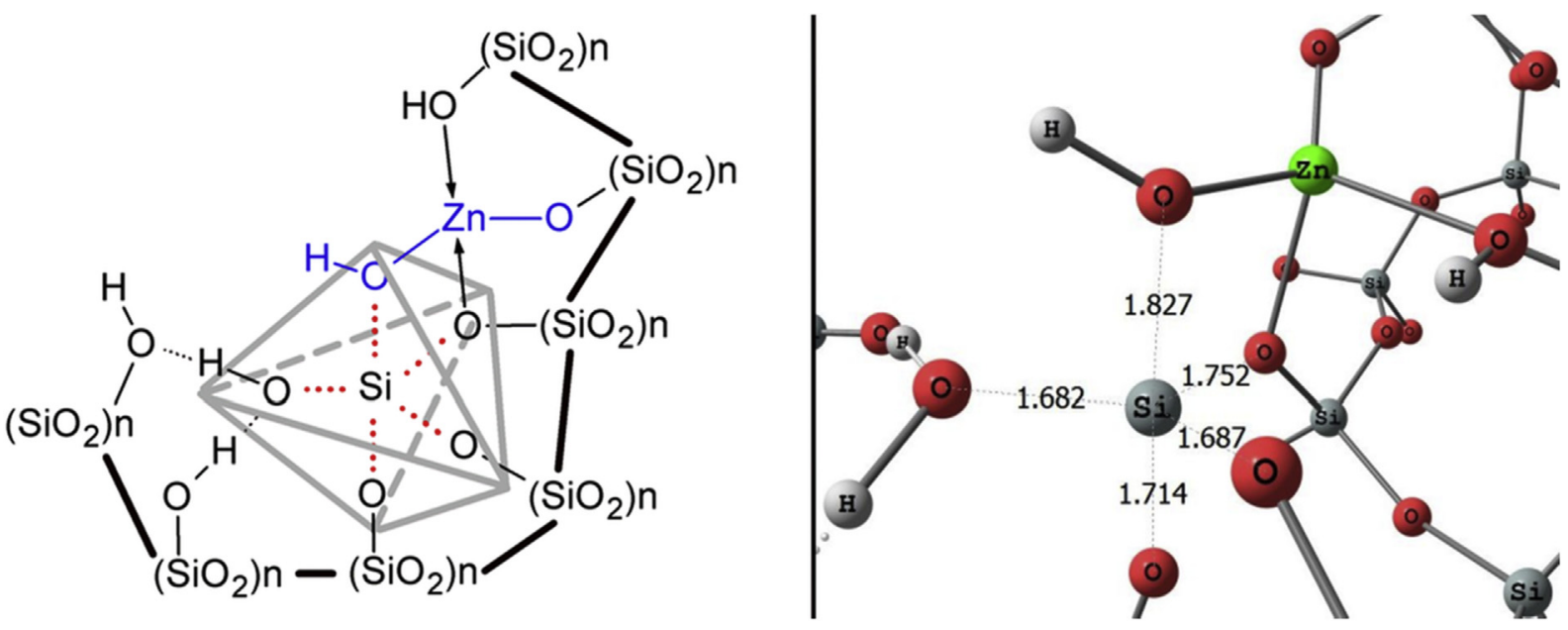

Fig. 6. The most stable species of $\mathrm{ZnO}$ grafted on a silica surface showing the penta-coordination of Si atom (interatomic distances in $\AA$ ).
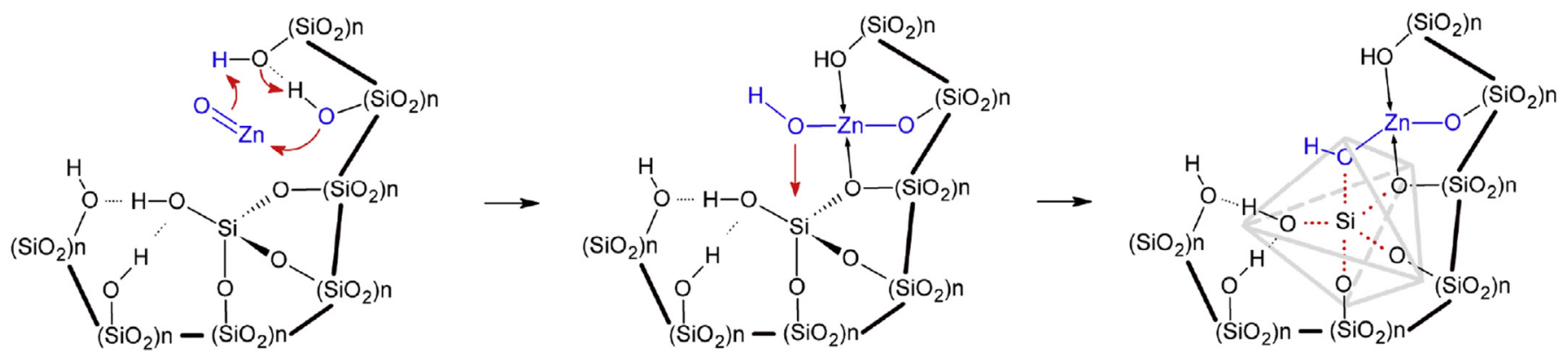

Fig. 7. The most plausible mechanism for formation of $\mathrm{Zn}-\mathrm{OH}$ species grafted to the silica surface. 